\title{
Correction to: Exponent of Cross-sectional Dependence for Residuals
}

\author{
Natalia Bailey \\ Monash University, Clayton, Australia \\ George Kapetanios \\ King's College London, London, UK \\ M. Hashem Pesaran
}

University of Southern California, Los Angeles, USA

Trinity College, Cambridge, UK

\section{Correction to: Sankhya B: The Indian Journal of Statistics 81(Suppl 1): 46-102}

https://doi.org/10.1007/s13571-019-00196-9

Note that in the definition of estimator $\tilde{\alpha}$ in Eq. 4.5 of page S56, the subsequent equation reads

$$
\tilde{\delta}_{i j}=\left\{\begin{array}{l}
1, \text { if }\left|\hat{\rho}_{i j}\right|>\frac{c_{p}(n, \delta)}{\sqrt{T}}, \text { for } i \neq j \\
1, \text { for } i=j \\
0, \text { otherwise }
\end{array} .\right.
$$

Publisher's Note. Springer Nature remains neutral with regard to jurisdictional claims in published maps and institutional affiliations.

NATALia BAILEY

MONASH UNIVERSiTy,

Clayton, Australia

E-mail: natalia.bailey@monash.edu

M. Hashem Pesaran

University OF SOUTHERn CALifornia,

Los ANGeles, CA, USA

Trinity College, Cambridge, UK

\section{George Kapetanios}

King's College London, LONDON, UK

The original article can be found online at https://doi.org/10.1007/s13571-019-00196-9. 